Jorge L. de Campos, Wallace V. da Silva [UERJ ]

\title{
O design e a representabilidade dos signos dentro da world wide web
}

\author{
Design and the representability of signs in the world wide web
}

Imagem, representação, mídia, internet.

O presente escrito discute as seguintes questões e idéias: 1) Há uma linguagem que seja característica da world wide web?; 2) Existe uma estética própria na world wide web? 3) A dicotomia, divergência ou ambigüidade nos signos da world wide web; 4) O caráter simbólico e literal dessas imagens. Apesar de a internet ser uma mídia recente, as questões envolvendo a imagem não são tão novas assim, remontando à litografia (des-re-construção da imagem) e à semiótica (caráter simbólico da informação). A própria internet enquanto 'nova mídia' é posta em questão, enquanto se estende o alcance da 'discussão da imagem' a todas as mídias existentes (incluindo a internet).

Image, representation, media, internet.

The present article discusses the following questions and ideas: 1) There is a world wide web characteristic language?; 2) There is on world wide web a own aesthetic?; 3) The dichotomy, divergence or ambiguity on world wide web signals; 4)The literal and symbolic aspects on these imagens. Althought internet be a recent media, questions involving the image are not so new, remonting from the litography (image des-reconstruction) until the semiotic (symbolic information character). The internet itself while 'new media' is questioned, while the image discussion is extended to all existent medias (internet included).

"O real não é verdadeiro, ser já o contenta."

H. Atlan

\section{Introdução}

Falar da imagem na internet é falar dos termos - segundo regras e atendendo a escopos bastante específicos - de sua 'concepção' e de sua 'fabricação' pelo homem contemporâneo. Porém, entender suas relações com o nosso cotidiano implica investigar as bases de sua inserção em um contexto maior - para além das fronteiras do design propriamente dito - cuja lógica remete, historicamente, aos primórdios da revolução industrial.

Como afirma Cardoso (2004, p.38, 39), o processo de industrialização acarretou mudanças mais incisivas do que uma simples reelaboração dos métodos produtivos. $\mathrm{O}$ incremento do contingente de indivíduos vivendo em espaços reduzidos alteraria a natureza de suas interrelações. Entre as mercadorias cujo consumo aumentou, a partir do século XIX, estão os impressos de toda espécie. Tais mudanças geraram desafios quanto à organização e à apresentação das informações. Entre eles, como sinalizar, adequadamente, a geografia expandida das cidades e como comunicar, para um público anônimo, os préstimos de produtos não conhecidos. Assim sendo, diversos avanços de ordem tecnológica vieram possibilitar, na expectativa de resolver essas e outras questões, a criação de veículos informacionais como os cartazes, as embalagens e as revistas. 
Entre as ainda incipientes tentativas de justapor o textual e o imagético - características do início do século XIX - e as sofisticadas programações que viriam à luz adiante, existem diferenças não só no que tange ao registro tecnológico. O impacto da técnica fotográfica sobre a comunicação visual se deu, igualmente, num plano conceitual, e o período foi marcado por uma crescente valorização sociocultural e econômica das imagens. Afinal, se a fotografia, por um lado, rematava o processo de sua transformação em mercadorias abundantes e baratas, por outro lado as privava de parte de seu tradicional peso simbólico.

O pós-guerra foi marcado pela consolidação de mídias relativamente novas - como o cinema e o rádio - ou inteiramente novas - como a televisão. Na música e no cinema, o disco (hoje o CD ou o DVD) acabaria tornando-se tão-somente um veículo para o verdadeiro produto que era a 'informação'. Tal ascensão do entretenimento a um status assumidamente econômico foi, por muitos anos, tratada como uma exceção às regras da produção industrial, a qual costumava ser pensada, sobretudo, em termos de bens duráveis. Com a ampliação da informática nas últimas duas décadas, passou-se a perceber que os conceitos tradicionais de 'produto' e 'design' haviam quase atingido os limites de suas próprias contradições.

Foi a partir da década de 1950 que a publicidade se assumiu como um fenômeno, simultaneamente, cultural e econômico. A introdução da televisão, nessa mesma época, ajudou a consolidar uma relação entre o design, a publicidade e o marketing. Foi em torno dela que se cristalizou o que foi chamado de lifestyle ou 'estilo de vida'. Trata-se da idéia de que uma mercadoria é uma peça inserida em toda uma rede de associações e atividades que geram tanto a imagem quanto a auto-imagem do consumidor-usuário.

Seja como for, não resta dúvida de que, hoje em dia, a imagem e a inserção do produto se tornaram tão importantes quanto a sua construção e a sua configuração e que, portanto, design, marketing e tecnologia passaram a andar juntos na era do capitalismo tardio. Os críticos contundentes do marketing moderno costumam dizer que, à medida que aumentam as opções de consumo, não resta ao consumidor outra saída que a de consumir mais. Uma das marcas registradas da pós-modernidade (ou, quem sabe, da hiper-modernidade) (Lipovetsky, 2004) seria o 'pluralismo', ou seja, uma abertura generalizada para as posturas novas e uma tolerância efetiva para as divergentes.

Diante das transformações ocasionadas pelas tecnologias mais recentes, a distinção tradicional entre 'design gráfico' e 'design de produto' tende a se esvaecer. Quando um designer é contratado para criar uma homepage ou um site na internet, gera um produto que, embora não seja gráfico - no sentido da impressão - e nem um produto - no sentido de ser um artefato tangível - é tanto produto no sentido de ser uma mercadoria, quanto gráfico no sentido de estar voltado para a transmissão de informações.

Uma das peculiaridades desse estado de coisas ambíguo é que, "curiosamente, o objeto virtual acaba sendo gerado por um processo muito mais artesanal do que ... industrial", ficando claro "que esse tipo de produção se encaixa ... em uma evolução de ordem industrial ... porém tardia". Se, por um lado, "a difusão mundial do modelo consumista americano ... depende da expansão contínua da produção e do consumo...", esse "mesmo ímpeto consumista que mantém o sistema em funcionamento é responsável pelo agravamento dos problemas ambientais..."; cabendo, portanto, "ao designer ... projetar soluções capazes de conciliar esses dois pólos aparentemente inconciliáveis" (Cardoso, 2004, p.nn).

A idéia de fragmentação que acompanha a estética da internet tem suas origens num passado recente.

Na era eletrônica, o objeto já não pode ser considerado uma unidade integral, nem do ponto de vista técnico e muito menos do ponto de vista estético ... A incompatibilidade de qualquer coisa com qualquer outra coisa talvez esteja prestes a passar, conforme atesta um universo sempre em expansão de filmes e videogames, em que todos os temas e tratamentos se misturam sem nenhum compromisso com ... a realidade, mas apenas ... [com] o realismo da experiência representada. (ibidem)

O mundo da era da informação é composto por visões parcelares e por fragmentos visuais cuja totalidade só pode ser reconstituída na mente de cada um e de modo passageiro. O grande símbolo de nossa época talvez seja mesmo a internet. Aquela fragmentação se manifesta, com clareza, na velocidade com que a superabundância de informações disponíveis vai, continuamente, sendo acrescida de outras informações e condenada à insignificância em razão do espaço proporcionalmente ínfimo que conseguem ocupar. Na realidade, o final do século XX 
definiu-se pela saturação imagética, pela poluição visual, pelo bombardeio semiótico da publicidade e pelo olhar como forma de consumismo.

Muitos consideram a fragmentação visual como um fenômeno típico da era eletrônica, porém suas raízes remetem, no mínimo, ao século retrasado. A evolução desse processo de fragmentação da informação pôde ser percebida no campo gráfico muito antes da introdução propriamente dita das tecnologias eletrônicas. Toda uma seqüência de técnicas e processos para a manipulação do texto e da imagem - que inclui a litografia, a rotogravura, o fotolito, o offset e outros recursos gráficos tradicionais - já envolvia a possibilidade de 'quebrar' e, depois, recompor núcleos de informação preexistente sem novas combinações, da colagem à história em quadrinhos.

Seja olhando para um outdoor, a partir de um trem em movimento, seja passando em revista os canais de televisão, a velocidade do olhar moderno pressupõe um processo de fragmentação e de sobreposição de imagens. Como meio de comunicação, a web lida, em função de sua conformação híbrida, concomitantemente, com aspectos práticos e simbólicos, comunicando valores de representabilidade concreta através de meios imateriais (imagens, sons, redes sociais etc.). Se tivéssemos de associá-la à figura de um animal, o camaleão seria uma escolha adequada, já que, a exemplo deste, ela pode ou não ser vista, conforme a situação e a necessidade, como um objeto visual; como ser vivo, adapta-se a qualquer ambiente novo; como objeto simbólico, representa conceitos como a permeabilidade, a adaptabilidade e a evolução (mutação), que parecem ser características cada vez mais necessárias num mundo globalizado e ultracompetitivo.

\section{Existe uma linguagem característica da world wide web?}

A designer Valéria London afirmou, em uma palestra, que os sites existentes eram, esteticamente, tão 'semelhantes' entre si que, em termos de design, "não havia o que se comentar" sobre o assunto. A internet explodia, então, comercialmente, no mundo, muito se produzindo, por igual, por toda parte do planeta. Tal ponto de vista ainda é compartilhado por bom quinhão dos profissionais da área. Cardoso observa que, independentemente dosdesafios do hipertexto, da navegação, da interatividade e da conjugação das linguagens gráficas com o som e a imagem em movimento ... boa parte da produção na área de webdesign já começa a empregar estratégias produtivas repetitivas ou previsíveis, [e] a própria metáfora de 'navegar' na rede [em inglês, emprega-se o termo 'surfar'] remete a uma noção de deslizar pela superfície sem nunca se aprofundar ou inovar, nem ir além. (ibidem)

Se formos analisar o fenômeno do ponto de vista da comunicação visual, perceberemos a existência, ao longo dos anos, de uma corrida, quase em paralelo, entre a tecnologia, a moda e as necessidades. Assim como a tecnologia no meio analógico chegou a definir, em alguns momentos, a própria apresentação do design (antes da invenção do clichê tipográfico reticulado para fotos, o design das páginas de jornal feitas em tipografia era, essencialmente, um 'texto'), na internet as coisas ocorreram de modo parecido.

De fato, o conteúdo da web era, no início, basicamente 'textual', estruturado em links (vínculos) e hyperlinks (hipervínculos), 1 um texto remetendo a outros, numa cadeia que a Wikipedia ilustra bem.2 Com os desdobramentos tecnológicos, novos programas para acessar conteúdos - os browsers (navegadores) - surgiram, permitindo a visualização de um conteúdo multimidial: imagens, áudio, vídeo e animações passaram a exigir uma melhor elaboração do layout das páginas. As tecnologias surgidas a partir daí permitiram que uma página da web se tornasse tão elaborada quanto uma página de revista ou de jornal impresso. A metáfora de página de livro cedeu lugar à metáfora do conteúdo de publicação diária. A biblioteca acadêmica cedeu lugar à banca de jornais, o jogo de papel e o cartão impresso foram substituídos pelos videogames.

Esse caminho veio a ser de mão dupla: assim como a web se apropriou da estética de mídias anteriores (como sempre ocorre no surgimento de uma nova mídia), elementos típicos da web - barras de informação textual e informação organizada em menus - passaram a invadir tudo, da televisão às capas das revistas de histórias em quadrinhos. Hoje, quando se fala de 'estética de internet', se fala, na verdade, de uma estética herdada dos jogos eletrônicos, da mídia 


\section{Infodesıgn}

impressa jornalística, da televisão e do CD-ROM. Esta, por sua vez, ao reunir esses e outros elementos, implementou uma linguagem própria, ao incorporar também a interatividade. O leitorespectador deixou de ser um receptor passivo, podendo agora, até mesmo interferir no conteúdo acessado, seja acrescentando comentários, seja personalizando páginas que, amiúde, altera, gerando conteúdo inéditos, algo que as outras mídias apenas faziam - ou tentavam, indiretamente, fazer - com o uso de duas mídias em paralelo (televisão e telefone, rádio e e-mail etc.).

Tal linguagem interativa é, pode-se dizer, hoje em dia, a principal característica da web, o fator que, com efeito, a distingue dos demais meios de comunicação. Mas, ainda assim, o que se deseja comunicar com ela? Provavelmente está ligada à mensagem que se busca passar. Num mundo cada vez mais baseado em imagens (que não aboliu, porém, a palavra no seu sentido estrito), pode-se dizer que a linguagem tem, sobretudo, o papel (ou o poder) de cativar ou de manipular a audiência, mais até do que de informá-la. Nesse sentido, a web objetivaria ser 'a mídia das mídias', ao sintetizar, nela mesma, o rádio, a televisão, o telefone, a revista, o jornal, o livro e o clube. A lista se tornará interminável se acrescentarmos subcategorias como os DVDs, os cartazes, as mensagens publicitárias, as músicas. Uma linguagem que dê conta disso tudo tem que ser, por excelência, multimidial.

Ora, se a internet consegue ser todas as mídias, sem ser nenhuma em especial, é, na realidade, uma 'nova velha mídia'. Sua linguagem pressuporia outras, ainda que herdadas de suas antecessoras. Esse camaleão teria, portanto, como característica não ter um rosto, ou seu rosto seria uma colagem de expressões várias? Tomemos como exemplo a televisão, a sua antecessora mais recente ou direta. A TV surgiu da reunião de mídias como o teatro, o rádio, o cinema e a publicidade. Mesmo sendo híbrida, sua polivalência criou uma nova linguagem, a televisiva, que subentende um naturalismo 'editado'. Seria então a web uma multimídia eletrônica? É possível dizer que sim, à maneira da TV aberta, só que interativa. Sua estética, por conseguinte, seria típica dos meios digitais atuais, ou "tranversal pós-massiva", como já sugerira André Lemos.3 Nesse sentido, seria facil entender a busca da interatividade nas demais mídias, assim como o surgimento de programas interativos na TV, ao mesmo tempo em que ocorre a explosão comercial da internet em nível mundial.

\section{Existe uma estética própria da world wide web?}

Se cada mídia contém elementos que a caracterizam por si mesma, ao analisar as páginas da web se percebe que os ícones possuem uma função análoga à dos sinais de trânsito. Assim como estes têm por finalidade orientar o fluxo de automóveis e pedestres, aqueles têm por função orientar a navegação dos internautas. Mas a analogia poderia parar aí, pois, no meio 'físico', os sinais se relacionam com o espaço tridimensional, articulando-se como uma referência e um referente, diversamente do (atual) espaço bidimensional da web. Não há como relacionar elementos nesse espaço da maneira como se costuma fazer no mundo real.

A estética da web seria um espaço semelhante a um tabuleiro de damas, onde se pode caminhar, linearmente, num mesmo plano, e o conteúdo se sobrepõe em pilhas como peças de dimensões idênticas. A ausência de planos é relativa, uma vez que as imagens (ou as janelas) se sobrepõem indefinidamente. Como não há profundidade real no espaço da web, tudo ali acaba, de certo modo, sendo 'raso' (quanto ao significado) e 'infinito' (a quantidade de informação armazenada).

Por ser um apanhado de tudo que havia antes, essa estética é uma colcha de retalhos muito bem costurada. Portanto, não há como descrevê-la linearmente, ou de uma maneira uniforme. A melhor metáfora talvez seja a de um mosaico, de um quebra-cabeça ou de um sistema não-linear qualquer - como o próprio hipertexto pressupõe - mas que, ao final, cria um tipo de unidade 'em si'. A reunião, em uma mesma página, de fotografia e de texto suscita uma unidade (e uma interação) diferente daquela que se obtém ao reunir uma animação com áudio, e assim por diante. Essa fragmentação acaba por definir uma estética que surge 'no momento' da interação com esse veículo e não antes. 
Jorge L. de Campos, Wallace V. da Silva | "O design e a representabilidade dos signos dentro da world wide web"

\section{A dicotomia nos signos da world wide web}

A web é uma mídia essencialmente 2D. Com a evolução da tecnologia, elementos bidimensionais começaram a ser apresentados sugerindo, estática ou animadamente, um falso plano 3D. Cabe aqui discutir como os signos visuais e lingüísticos se articulam e também sua interação no meio, digital ou não, de comunicação. As coisas podem ter uma relação de 'semelhança' ou de 'similitude', como explica o pintor belga René Magritte numa carta endereçada, em maio de 1966, ao pensador francês Michel Foucault:

As palavras Semelhança e Similitude permitem sugerir com força a presença absolutamente estranha - do mundo e de nós. Entretanto, creio que essas duas palavras não são muito diferenciadas, os dicionários não são muito edificantes no que as distingue. Parece-me que, por exemplo, as ervilhas possuem relação de similitude entre si, ao mesmo tempo visível (sua cor, forma, dimensão) e invisível (sua natureza, sabor, peso). O mesmo se dá no que concerne ao falso e ao autêntico etc. As 'coisas' não possuem entre si semelhanças, elas têm ou não têm similitudes. Só ao pensamento é dado ser semelhante. Ele se assemelha sendo o que vê, ouve ou conhece, ele torna-se o que o mundo Ihe oferece. (Foucault, 1988, p.28)

A imagem e o texto podem ter similitudes (nos planos do conteúdo e da percepção) na medida em que a primeira pode ser lida como um texto e vice-versa, conforme sua apresentação ou sua interpretação. A esse respeito, Jorge Lúcio de Campos afirma quesão oferecidos dois níveis de leitura e de interpretação: relação de dupla captura, entre o texto e a imagem, subrepticiamente configurada, em ambos os quadros, pelas possibilidades lógico-semiológicas de consideração simultânea de uma 'imagem escrita' (regida pela verossimilhança lingüística) e de uma frase 'pintada' (regida pela verossimilhança plástica). (Campos, 2005, p.nn)

O conceito de caligrama - caligrafia e ideograma, texto e imagem - faz sentido nesse ponto de vista.

Campos acrescenta que a inevitável relação entre o texto e o desenho faz lembrar uma operação caligramática, em que palavras e imagens se completam para dizer algo em conjunto, com as linhas composicionais conformando-se a partir do que é descrito textualmente. Os caligramas, por sua natureza híbrida, garantiriam uma dupla captura da qual não são capazes os discursos por si sós e os desenhos em sua pureza visual. Comportar-se-iam antes como uma escrita que lança no espaço a visibilidade provável de uma referência, invocando os signos, do âmago da imagem que configuram - por um recorte de sua massa na página - aquilo de que falam. (ibidem)

Do passado caligráfico, as palavras conservariam sua derivação linear e seu estado de coisa desenhada. Contudo, sob tal ótica, não passariam de palavras que 'desenham' outras palavras, de um texto em forma de imagem:

Ao lermos o texto, não perceberemos o (seu) desenho e, ao olharmos o desenho, as palavras parecerão perder seu sentido textual para assumir o papel de linhas estruturantes. Um leque hermenêutico, que estaria fechado num interior significante, é, enfim, ardilosamente, aberto e tornado freqüentável ... é preciso que haja uma subordinação: ou o texto será regrado pela imagem ... ou a imagem o será pelo texto (que o desenho vem completar, como se encurtasse um caminho que as palavras estariam encarregadas de representar). O signo verbal e a representação visual jamais seriam dados de uma só vez. Sempre uma ordem os hierarquizaria, indo da forma ao discurso ou do discurso à forma ... Tratar-se-ia ... do cruzamento, num mesmo tecido, do sistema da representação por semelhança e da referência pelos signos - o que supõe que eles se encontram num espaço completamente diverso daquele. (ibidem)

Segundo Mihaly Csikszentmihalyi e Eugene Rochberg-Halton, a ambigüidade das relações do homem consiste no fato de que este "não é apenas um homo sapiens ou um homo ludens, mas também um homo faber, simultaneamente, 'fazedor' e usuário de objetos. Sua subjetividade é, de certa forma, um reflexo das coisas com as quais interage" (Csizsentmihalyi \& Rochberg-Halton, 1998, p.1). Sendo assim, os objetos também fariam e usariam seus criadores e usuários na manutenção do sistema do status e do sistema (de diferenciação social) em si.

Para Luiz Antonio Coelho, os objetos teriam o poder de induzir e refletir as qualidades que, simbolicamente, representam, pois nos representam em dois níveis, como reflexo e indutor, para nós mesmos e para o social. Isso porque "transferimos sonhos e expectativas para o objeto. Tanto 


\section{Infodesıgn}

em sua fabricação quanto em seu uso, refletimos nossas tendências e apreço pessoal e social" (Coelho, 2006, p.156). O elemento que propicia essa postura é a tecnologia: a mesma que fez prevalecer a estandardização, trazendo a automação para o processo (produtivo), agora aponta para o seu reverso.

Coelho lembra que deixamos rastros na passagem pela vida. Rastros do que fazemos, no que fazemos e de como fazemos. Os vestígios que deixamos impregnados nos objetos podem ser, portanto, marcas semânticas, verdadeiros signos de época. Quando o artesão estava próximo do usuário no período pré-industrial, os aspectos simbólicos - além do uso - fundiam-se no próprio uso. Com a industrialização, houve uma ruptura nessa relação de proximidade e, com ela, uma separação na semiose. Um determinado produto ou classe enquanto signo passou a ser um signo-gênero, superestrutural (ibidem, p.160-161).

Esse autor também lembra que, em uma fase posterior do processo industrial (a partir da década de 1980), passou-se a contemplar a intervenção direta do usuário no processo de fabricação. Aqui a idéia central reside no deslocamento da atenção do autor para o receptor, do texto para a recepção, do fabricante para o usuário e do produto para o uso. Por fim, do "objeto de uso individual para o de uso coletivo", havendo três funções (ou graus de importância): a prática, a estética e a simbólica (ibidem).

O computador e seu texto virtual subverteram os aspectos simbólicos que afetam a maneira como o objeto é visto pelo usuário. Com o seu advento, a idéia do texto escrito como um corpo, uma realidade física, simplesmente, deixou de existir, e uma 'falta de paciência' em relação ao texto teve vez, assim como uma tendência a lê-lo mais displicentemente, (pois) o scrolling (rolagem) facilitou o acaso da leitura.

Mas qual seria o limite desse processo, que visa a diferenciação extrema dos objetos (já reduzidos a imagens) e a individualização absoluta em sua produção? A solução talvez fosse "a busca de uma negociação homeostática entre os dois extremos desintegradores: o da massificação robotizante e do atomismo exacerbado. Nesse sentido o equilíbrio estaria nas mãos da tecnologia adotada pela indústria..." (ibidem), no designer, que medeia esses processos, e no objeto, que atua no centro deste palco.

\section{Caráter simbólico e literal}

A apresentação da web em monitores CRT (convencional) e agora em LCD (tela fina, de cristal líquido) confere às imagens uma beleza ou realismo antes exclusivos da fotografia, do cinema ou da TV. Esse caráter hiper-realista conferido pelas imagens da internet é apenas um dos aspectos que explicariam o fascínio da web em relação às mídias antecessoras (a impressa, como o jornal).

A importância de alguns objetos muda ao longo da vida, visto que a necessidade e o desejo de representar papéis também se modificam. É praticamente impossível consumir produtos sem significados e, em conseqüência, não comunicar ou exercer qualquer papel ao adquiri-los e utilizá-los. Nada tem valor por si mesmo. Este é outorgado por humanos, dependendo o valor de um produto de seu lugar e tempo na sociedade de consumo.

Para Coelho, o lado 'prático' dessa sedução da imagem pode ser medido pelo consumo por ela gerado. O consumo é um fenômeno simbólico e cultural que predomina sobre a necessidade, sendo o mais poderoso sistema de classificação social. É o sistema que classifica as coisas e as pessoas. Desta forma, gera representações coletivas, emoções codificadas, sentimentos obrigatórios e pensamentos. Tornou-se a forma como a sociedade se comunica. Mais do que uma mensagem, converteu-se no sistema em si.

Katia Faggiani sustenta que os significados imputados aos produtos se multiplicaram, superando suas características funcionais. O mundo do consumo é um conjunto de signos e de significados interligados e interdependentes que oferece uma maneira de socialização aos indivíduos (Faggiani, 2006, p.10). Para ela, os produtos preenchem nossas necessidades emocionais porque vão além das necessidades mecânicas, utilitárias e funcionais, proporcionando uma sensação de glória ou de satisfação. Em nossa sociedade, o grau de sucesso é medido pela quantidade de riquezas e de consumo. Consumidores modernos se identificam pela fórmula: "eu sou igual ao que tenho e ao que consumo". Consumir, agora, é igual a possuir, pois o ser humano não responde às qualidades físicas das coisas e, sim, ao que elas significam para ele. Em outras palavras, não consumimos produtos, mas a imagem que temos deles (ibidem). 
Assim, para Faggiani, conceitos como luxo, consumo e imagem agora se entrelaçam. $\mathrm{O}$ consumo (mediado pela imagem) nos humaniza, demonstrando que somos regidos por outras necessidades, além de comer e beber. O consumo nos diz que somos superiores, que nossas necessidades são humanizadas. Isso leva ao conceito de 'masstígio', combinação de (consumo de) 'massa' e 'prestígio', ou seja, 'prestígio para as massas', um alto prestígio diferenciado para consumo de massa, a preços mais altos, mas não impossíveis de serem pagos (ibidem).

A autora assevera que o consumo de imagens é um degrau para o consumo de produtos. Este se transforma num ritual de busca de um novo estilo de vida (que nos diferenciaria, finalmente, dos outros animais). O importante não é tanto 'ter' quanto 'parecer'. Os objetos se confundem com as pessoas a ponto de elas passarem, de certo modo, a ser o que 'usam'. Em qualquer sociedade, de qualquer época, os aspectos materiais não se separam dos sociais, unificados pela dimensão simbólica que, por ser constituída (e constituinte), é, portanto, in essentia, flexível.

Os significados são transmitidos pelas imagens (ou pelos produtos, pois não há muitas diferenças entre ambos) e são parte integrante do propósito de controlar a informação. Contudo, só podem revelar seus reais significados se examinados em conjunto. Faggiani lembra que, como a imagem é informação e se articula através da cultura, esta última constitui o mundo suprindo-o com sentidos que se apóiam em categorias e princípios culturais.

Porém, seria preconceituoso e limitado atribuir ao design os méritos e os deméritos por tal estado de coisas. Seria, mais ou menos, como responsabilizar a violência pela existência dos criminosos (os efeitos múltiplos por uma causa única). O design, a publicidade e os meios de comunicação, lembra ainda Faggiani, "são mecanismos muito poderosos para a transferência de significados, a ponto de poderem atribuir qualquer significado a qualquer produto. Eles criam mitos oriundos do contexto cultural" (ibidem).

Através da cultura, com um repertório calcado, sobretudo, nas imagens, os meios de comunicação (não só o design, que trabalha, basicamente, com dois tipos de comunicação, a visual e a de produto) completam uma transição dos meios de produção para os meios de consumo através de um processo de transferência e de classificação de significados, socializando o consumo.

\section{Considerações finais}

Segundo Fredric Jameson, mais recentemente, "a fotografia, o cinema e a televisão começaram a se infiltrar na ... arte visual e a colonizá-la, produzindo híbridos altamente tecnológicos de todos os tipos..." (Jameson, 1994, p.nn). É o momento da sociedade da imagem, na qual, segundo Paul Willis, os sujeitos humanos, já expostos ao bombardeio de até mil imagens por dia, vivem e consomem a cultura de maneiras novas e diferentes. O caráter de reflexividade dessas imagens como tal submerge na pura superabundância. A ilusão de uma nova naturalidade surge, quando já não há nenhuma distância em relação à cultura das imagens, quando já não podemos reconhecer a singularidade histórica ou a originalidade de nossa época. A nova situação, onde o estético a tudo impregna, onde a cultura se expande - a ponto de tudo se tornar aculturado de uma forma ou de outra - toda a realidade se tornou profundamente visual.

Jameson recorda, pertinentemente, que a concisão da linguagem do vídeo e a natureza essencialmente operística da cultura da imagem televisiva (como na MTV) parecem transformar a fragmentação de narrativas mais antigas em fragmentos puros de narratividade, visualmente autônomos e narrativamente auto-significativos. Para um público saturado com as imagens comerciais e com um sofisticado acervo-memória de cultura, uma só tomada seria suficiente para desencadear a associatividade que tinha de ser construída no decorrer de toda uma obra (ibidem).

Ele também recorda que a sociedade dos espetáculos ou das imagens é - ao menos em parte - definida pela transformação maciça da beleza em objeto de consumo. O meio visual constitui o veículo através do qual vários públicos são seduzidos e 'interpelados'. É o próprio visual que abstrai esses públicos de seus contextos sociais imediatos, criando a sensação de uma imaterialidade e de uma concretude cada vez maiores, já que o que se consome não é uma abstração verbal, mas sim, a imagem tangível (ibidem). 


\section{Infodesıgn}

Uma das conclusões a que podemos chegar é que projetar para a internet - criar artefatos para uma sociedade de consumo baseada na tecnologia - pressupõe a configuração de significados aos comportamentos. As imagens, sob o aspecto simbólico, são elementos formadores-determinantes dos estilo de vida e dos valores de troca. Por conseguinte, podem existir, no mínimo, dois níveis de leitura de uma imagem: um no âmbito da atribuição e o outro no da apropriação. O primeiro se refere aos processos de produção e distribuição, que dizem respeito a valores universais e inerentes, e o segundo é relativo aos processos de consumo e de uso, a valores pessoais e inconstantes.

Finalizando o raciocínio de Jameson, a relação de fetichismo frente à imagem (na web) se explicaria, nesse sentido, como uma agregação de valores subjetivos ao objeto e como uma apropriação de valores subjetivos representados pelo próprio objeto ou por sua imagem ou pelos que nele são introduzidos.

\section{Referências}

Aumont, J. (2001). A imagem. Campinas: Papirus.

Campos, J. L. de. (2005). Eis dois cachimbos: roteiro para uma leitura foucaultiana de Magritte. In: Poièsis - Estudos de Ciência da Arte (EdUFF), v.8.

Cardoso, R. (2004). Uma introdução à história do design. São Paulo: Edgard Blücher.

Coelho, L. A. Objeto com afeto. In: Coelho, L. A.; Lima, G. C. (Org.) (2006). Textos selecionados de design, v.1. Rio de Janeiro: PPDESDI, UERJ.

Csizsentmihalyi, M.; Rochberg-Halton, E. (1998). The meaning of things. Domestic symbols and the self. Cambridge: Cambridge University Press.

Faggiani, K. (2006). O poder do design. Brasília: Thesaurus.

Flusser, V. (2002). Filosofia da caixa preta. Rio de Janeiro: Relume Dumará.

Flusser, V. (2007). O mundo codificado: por uma filosofia do design e da comunicação. São Paulo: Cosac Naify.

Foucault, M. (1988). Isto não é um cachimbo. Rio de Janeiro: Paz e Terra.

Harvey, D. (1992). A condição pós-moderna: uma pesquisa sobre as origens da mudança cultural. São Paulo: Loyola.

Jameson, F. (1994). Transformações da imagem na pós-modernidade. In: Jameson, F. Espaço e imagem: teorias do pós-moderno e outros ensaios. Rio de Janeiro: Ed. UFRJ.

Lipovetsky, G. (2004). Os tempos hipermodernos. São Paulo: Barcarolla.

Mitchell, W. T. (1992). The reconfigured eye: visual truth in the post-photographic era. Princeton: MIT. 34.

Parente, A. (2001). A imagem-máquina: a era das tecnologias do virtual. Rio de Janeiro: Ed.

Virilio, P. (1994). A máquina de visão. Rio de Janeiro: J. Olympio Ed. 
Jorge L. de Campos, Wallace V. da Silva | "O design e a representabilidade dos signos dentro da world wide web"

\section{Sobre os autores}

\section{Jorge Lucio de Campos}

Doutor e Pós-Doutor em Comunicação e Cultura (História dos Sistemas de Pensamento) pela UFRJ (1996). Mestre em Filosofia (Estética) pela UFRJ (1988). Graduado em Filosofia pela UFRJ (1981). Professor do Programa de Pós-graduação (Mestrado) em Design da Esdi/Uerj.

\section{Wallace Vianna da Silva}

Aluno do Programa de Pós-Graduação em Design (Mestrado) da Esdi/Uerj. Designer graduado pela Esdi/Uerj. 